\title{
22. COMMISSION DES METEORES ET METEORITES
}

Acting President: P. M. Millman.

SECRETARY : I. Halliday.

\section{Report of Business Sessions, 26 August 1964}

The first session of Commission 22 was held at $\circ 9^{\mathrm{h}} \circ 0^{\mathrm{m}}, 26$ August 1964 , with approximately 40 members and guests present. P. M. Millman, Vice-President, was in the chair. A letter from the President, Dr V. V. Fedynsky, was read. This expressed his regret at his inability to attend the sessions. The Chairman agreed to write Dr Fedynsky and to convey best wishes from members of the Commission.

Copies of the Draft Report, including the Report of Committee (a) on Meteorites, were distributed to members of the Commission who were asked to submit as soon as possible suggested corrections or additions.

The Executive Committee nominations for President and Vice-President of Commission 22 for the 1964-1967 term were reported, and a list of names for consideration for appointment to the Organizing Committee of Commission 22 was proposed.

L. G. Jacchia reported that the continuation of Committee $(b)$ on Terminology was no longer essential although some discussion on this subject by the Commission might be beneficial. The relationship of Commission 22 to Commissions 2 I and 44 was discussed.

The Chairman asked members to review the list of recommendations in the Draft Report for consideration at the second session.

The second session of Commission 22 was held at $15^{\mathrm{h}} 45^{\mathrm{m}}, 26$ August. The Chairman presented a revised list of 10 recommendations, compiled by a working group from the Commission. After a brief discussion and minor amendments, these were approved.

Following comments on the desirability of a broad geographical and professional representation, the following names were selected by the Commission to form the Organizing Committee:

$$
\begin{array}{ll}
\text { Babadjanov, P. B. } & \text { (U.S.S.R.) } \\
\text { Ellyett, C. } & \text { (New Zealand) } \\
\text { Fireman, E. L. } & \text { (U.S.A.) } \\
\text { Guigay, G. } & \text { (France) } \\
\text { Lindblad, B. A. } & \text { (Sweden) }
\end{array}
$$

E. L. Fireman was named as Chairman of Committee (a) on Meteorites for the $1964-1967$ term, and E. L. Krinov was named Vice-Chairman.

The Chairman reported that, since the first session, he had consulted with the President of Commission 44 and it was mutually agreed that the subject of small solid particles or dust observed from spacecraft would, in general, be discussed in Commission 22 and not in Commission 44 .

The meeting concluded with a short discussion on the terminology of the various types of solid particles, often considered under the general term 'meteoric dust'. Comments from members were invited on this topic.

A third session for the presentation of brief scientific papers was organized for $\mathrm{I}^{\mathrm{h}} \mathrm{oo}^{\mathrm{m}}$ on I September. 


\section{RECOMMENDATIONS}

1. To publish, for 100 meteors from the large quantity of homogeneous data secured with the Super-Schmidt cameras, curves of the absolute values of photographic brightness as a function of time and height.

2. To intensify the study of meteor spectra, with emphasis on the atmospheric and persistent train features.

3. To check the existence of the dust clouds observed by Kordylevsky at the points of libration in the lunar orbit.

4. That, in studies of interplanetary dust from spacecraft and rockets, special attention be paid to its mass distribution, its velocity distribution, and its concentration near the Earth.

5. That, wherever possible, national or regional organizations be set up to assist in the search for and recovery of meteorites that may have fallen after the appearance of a very bright fireball; further, that in this connection use be made of existing institutions such as astronomical and geophysical societies, meteorological stations, radio broadcasting systems and the local newspapers.

6. To report immediately new falls and finds of meteorites to the Permanent Commission on Meteorites of the International Geological Congress (E. L. Krinov, Committee on Meteorites of the Academy of Sciences of the U.S.S.R.-Ulitza M. Ul'ianovoy 3, korpus I, Moscow W-313, U.S.S.R.) for publication in the Meteoritical Bulletin, the data to include:-name, place, date, class and type, number, size and weight, and brief circumstances of fall or find.

7. To encourage the collection and study of meteoritic dust in the area of meteorite falls and meteor craters.

8. To emphasize the importance of sending, as rapidly as possible, freshly fallen meteoritic material to laboratories making isotope studies, and to compile and circulate a list of such laboratories.

9. To revise and update the Prior-Hey Catalogue of Meteorites, and edition, British Museum (Natural History), I953.

ro. To encourage a more intensive study of proven meteor craters by all modern techniques, including drilling, seismic and magnetic studies, gravity survey, and the age determination of materials. 